\title{
Erratum to: Ethical Considerations in Stem Cell Research on Neurologic and Orthopedic Conditions
}

\author{
John D. Banja
}

\section{Erratum to:}

Chapter 6 in: P.V. Pham, A. Rosemann (eds.), Safety, Ethics and Regulations, Stem Cells in Clinical Applications, DOI 10.1007/978-3-319-59165-0_6

The original version of this reprinted chapter was inadvertently published without the necessary credit information. The chapter has now been corrected and included the following credit line.

"Reprinted from $P M \& R$ Journal, Vol. 7 issue 4S, Banja J.D., Ethical considerations in stem cell research on neurological and orthopedic conditions, S66 - S75, 2015 with permission from Elsevier."

The updated online version of this chapter can be found at http://dx.doi.org/10.1007/978-3-319-59165-0_6 